\title{
Information provision, patient involvement, and emotional support: prospective areas for improv- ing anesthetic care
}

[L'accès à l'information, la participation du patient, le soutien émotionnel: des secteurs potentiels d'amélioration des soins anesthésiques]

Heather D. Hadjistavropoulos PhD, ${ }^{*}$ Joy Dobson MD,† Jennifer A. Boisvert BA(hons)

Purpose: To explore patients' perceptions of anesthetic care as measured by a patient-centered care survey. Specifically, the survey examined patient views of multiple diverse dimensions of care that are not typically fully addressed among patients receiving anesthesia services, namely opinions on Information Provision, Involvement in Care, Respect Shown, Physical Comfort, and Emotional Support. Method: A total of 268 patients responded to a patient-centered care survey, a self-report factor analytically derived instrument designed to measure the aforementioned dimensions of care.

Results: Analyses revealed that the highest ratings of care were given to Physical Comfort and Respect. Ratings of Information Provision, Involvement, and Emotional Support were significantly lower. Ratings did not differ as a function of site of service, inpatient vs day surgery, surgical service, type of anesthetic, or anesthesiologist.

Discussion: The findings generated from the study are of value in obtaining a broader understanding of anesthesia services from the patient's perspective, and also in directing quality improvement initiatives. Other departments of anesthesiology interested in quality improvement initiatives may similarly benefit from measurement of patient-centered care.

Objectif : Explorer la façon de percevoir les soins anesthésiques au moyen d'une enquête axée sur les patients. Lenquête a spécialement étudié le point de vue des patients sur différentes dimensions des soins qui ne sont pas généralement examinées, à savoir l'accès à l'information, la participation aux soins, le respect, le confort physique et le soutien émotionnel.

Méthode : Ce sont 268 patients qui ont répondu à cette enquête axée sur les patients. Nous avons utilisé un instrument dérivé analy- tiquement d'un facteur auto-déclaré pour mesurer l'importance des soins susmentionnée.

Résultats : Les plus hautes cotes sont allées au confort physique et au respect. Les cotes sur les informations, la participation et le soutien émotionnel ont été significativement plus basses. Les cotes n'ont pas présenté de différence en fonction du lieu, du fait d'être un patient hospitalisé ou ambulatoire, du type de chirurgie ou d'anesthésie ou de l'anesthésiologiste.

Conclusion: Les résultats de l'étude sont précieux, car ils permettent de mieux comprendre les services anesthésiques du point de vue du patient et aussi d'orienter les initiatives d'amélioration de la qualité. D'autres services d'anesthésiologie intéressés à ce genre d'action pourraient bénéficier d'une enquête semblable.

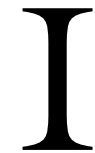

NCREASINGLY, health care providers are striving to provide patient-centered care in an effort to enhance quality of service provision. ${ }^{1-3}$ Patient-centered care is an approach to care focused on service providers' incorporation of patientperceived needs, priorities, or expectations into the provision of health care services. ${ }^{4}$ Based on extensive research with patients, this involves guaranteeing respect for patients' values, preferences, and expressed needs; coordinating and integrating care; sharing information/education; providing physical comfort; addressing emotional concerns; involving family members and friends; and ensuring continuity of care. ${ }^{5}$

For care to be patient-centered, it is important for health care providers, including anesthesiologists, to

From the Clinical Research and Development Program, ${ }^{*}$ and the Department of Anesthesiology, $†$ Regina Health District, Regina, Saskatchewan, Canada.

Address correspondence to: Dr. Heather D. Hadjistavropoulos, Associate Professor, Deptartment of Psychology, University of Regina, Regina, Saskatchewan S4S 0A2, Canada.

Phone: 306-585-5133; Fax: 306-585-4287; E-mail: hadjista@vregina.ca

Accepted for publication January 23, 2001

Revision accepted July 9, 2001. 
display sensitivity towards patient perspectives and offer care that is congruent with patient-perceived preferences or concerns. ${ }^{4}$ The implication of this is that it is necessary to explore anesthesia services from the viewpoint of those who receive service as a means of optimizing quality of care from their perspective. This position is consistent with that expressed by others who have suggested that service recipients rather than service providers are in the best position to evaluate performance excellence. ${ }^{6,7}$

Although there have been numerous studies of patient satisfaction with various aspects of anesthetic care, such as provision of information, quality of recovery, and pain management, ${ }^{8}$ to our knowledge very few studies have examined the degree to which anesthetic care is patient-centered. Patient satisfaction is typically used to refer to whether health care recipients' react positively or negatively to their care. ${ }^{9}$ At times, patients complete single-item global ratings of satisfaction, whereas, in other instances, multi-item questionnaires have been used. Recently, attempts have also been made to study surgeon satisfaction with the provision of anesthetic care in terms of both clinical expertise and attitudes and behaviour. ${ }^{10}$ The purpose of this latter work was to explore whether surgeons were satisfied with services provided by anesthesiologists.

Assessment of patient-centered care differs from measurement of satisfaction in that the focus is on assessing patient experiences or interactions with the health care system in terms of multiple dimensions of care that patients have identified as important and essential to their health care experience. ${ }^{5}$ Recently, Asmundson and Jones ${ }^{11}$ developed the Wascana Client-Centered Care Survey (WCCS) for the assessment of multiple dimensions of patient-centered care. This survey may prove to be of practical value in evaluating patients' perspectives of anesthesia services, as it is designed to provide an efficient and psychometrically sound assessment of patient-centered care. The article explores information gained by studying patients' perceptions of anesthetic services as measured by the WCCS and demonstrates how this information can be of value in gauging anesthesia services and directing quality improvement initiatives.

\section{Method}

All patients discharged from hospital between January 1, 2000, and March 31, 2000, who underwent an anesthetic (including general, epidural, spinal, neuroleptic, and regional) as part of their inpatient or day surgery at Pasqua Hospital (PH) or Regina General Hospital $(\mathrm{RGH})$ were eligible for inclusion in the study $(n=3,279)$. There were 19 anesthesiologists who provided services to between 67 to 285 patients during the three-month period. To obtain the sample, a random selection of 50 patients was made from the patient lists of each anesthesiologist. The one exception to this was a locum anesthesiologist who provided services to 44 patients, in which case all patients were sampled. Anesthetic type was then examined and a number of additional patients were randomly selected to ensure that each type of anesthetic was adequately represented ( $n$ of at least 50 ).

In July 2000, the survey was mailed to the selected sample of RHD patients. The mail-out packages included a cover letter providing information about the study, the survey, and a self-addressed stamped envelope in which to return the completed survey. A follow-up letter was not sent out to respondents since others have found that while follow-up letters increase the response size they may actually reduce the representativeness of the sample. ${ }^{12}$

The WCCS $^{11}$ was used to examine patient perceptions of anesthetic care. This brief self-report measure was initially developed for use with rehabilitation clients and consisted of 20 items. All scale items are rated on a I (strongly agree) to 5 (strongly disagree) scale with lower scores reflecting higher ratings of patient-centered care. In addition to providing ratings of care, patients are also given the opportunity to provide written comments regarding their care. Factor analysis of the 20 items found support for four subscales including Information, Involvement in Care, Respect, and Community Transition. ${ }^{13}$ The measure was then subsequently expanded to include 40 items, and succeeding factor analytic investigations supported the existence of six subscales including Information Provision, Involvement in Care, Respect, Community Transition, Physical Comfort, and Emotional Support. ${ }^{11}$ With minor changes to wording, the WCCS has been used with various patient populations in a variety of settings including Medical Convalescence, Respiratory Medicine, Renal Dialysis, Cardiac Care, Neuroscience, Oncology, Maternal/Newborn, Pediatrics, Children's Rehabilitation, Adolescent Treatment Units, and Community Care. Subscales on all versions have been found to have strong internal consistency (e.g., alphas $>0.80$ ), face validity, factorial validity, and discriminative distinctiveness. Furthermore, the subscales have been found to be sensitive to detecting changes in perception of care over time. For the purposes of the present study, the survey was modified as has been done with other groups to be appropriate for patients to rate their anesthetic care (see items listed in Table II). The face validity of the tool was improved by eliminating some non-relevant items that focused on community transi- 
tion and integration (seven items), as well as rewording items to ask about the anesthetic. Furthermore, two items were added to the physical comfort subscale regarding side effects and complications ("I experienced no negative side effects of the anesthetic" and "There were no complications related to the anesthetic"). Scale items are listed in Table II.

\section{Results}

In total, 1,018 surveys were sent to patients. A number of questionnaires were returned uncompleted $(n=53)$ for a variety of reasons, including (a) no recollection of the surgery $(n=4)$ or the anesthesiologist $(n=12)$; (b) cognitive or mental health concerns that interfered with questionnaire completion $(n=10)$, (c) death following surgery $(n=2)$; (d) questionnaires returned unopened $(n=22)$; or (e) questionnaires returned indicating lack of willingness to participate $(n=3)$. In total, 268 surveys were returned completed. For each anesthesiologist, nine to 20 patients completed surveys, with response rates examined by anesthesiologist ranging from $18 \%$ to $43.5 \%$. Overall, the response rate was $26 \%$. This is not an atypical response rate for mail-out surveys and is felt to be an acceptable rate that enables examination of perceptions of care. ${ }^{12}$

The average age of respondents was $53.6 \mathrm{yr}$ $(\mathrm{SD}=21.4)$, with $63.9 \%$ of the sample being female. In terms of site and nature of surgery, $47 \%$ of surgeries were carried out at RGH as inpatient surgeries, $19.9 \%$ at $\mathrm{RGH}$ as day surgeries, $19.5 \%$ at $\mathrm{PH}$ as inpatients, and $13.5 \%$ at $\mathrm{PH}$ as day surgeries. The breakdown of the sample by service area and anesthetic type is presented in Table I. Characteristics of respondents were compared to those of non-respondents. Chi-square analysis showed that respondents were more likely to be female than non-respondents $\left(63.9 \%\right.$ vs $53.6 \%,^{2}$ $(\mathrm{l})=8.53, P<0.01)$. An independent sample $t$ test showed that respondents were also older than nonrespondents (53.6 vs 46.6, $t=-4.1, P<0.0001$ ). No other differences between respondents and nonrespondents emerged.

As noted above, the WCCS was modified in order to increase the face validity of the scale. In order to ensure, at least in part, that the modified WCCS retained its psychometric properties, we examined Chronbach's Alpha for internal consistency for the modified subscales. Chronbach's Alpha ranged from 0.86 to 0.94 , depending on the subscale examined: Information 0.91, Involvement 0.86, Respect 0.91, Physical Comfort 0.87, and Emotional Support 0.94.

Means and standard deviations on each of the subscales of the WCCS are reported in Table III. Examination of the means shows that patients, on aver-
TABLE I Frequency of respondents by service area and anesthetic type

\begin{tabular}{lll}
\hline Surgery service & Frequency & Percentage of sample (\%) \\
\hline Cardiovascular/thoracic & 12 & 4.5 \\
ENT & 5 & 1.9 \\
General medicine & 7 & 2.6 \\
General surgery & 50 & 18.8 \\
Neurosurgery & 21 & 7.9 \\
Obstetrics/gynecology & 50 & 18.8 \\
Ophthalmology & 26 & 9.8 \\
Orthopedic surgery & 33 & 12.4 \\
Pediatric & 13 & 4.9 \\
Plastic surgery & 10 & 3.8 \\
Psychiatry & 4 & 1.5 \\
Urology & 27 & 10.2 \\
Vascular surgery & 8 & 3.0 \\
Anesthetic type & & \\
\hline General & 204 & 76.7 \\
Spinal & 23 & 8.7 \\
Regional & 17 & 6.4 \\
Epidural & 13 & 4.9 \\
Neuroleptic & 9 & 3.4 \\
\hline
\end{tabular}

age, felt that they were provided with adequate information, they were sufficiently involved in their care, shown respect, and their physical and emotional needs were met. On average, no subscale score fell below 2.0, which indicates reasonable perceptions of patient-centered care. Examination of subscales scores revealed that there was no evidence of outliers in the data set (e.g., individual subscale scores with excessively large standardized scores). Examination of the subscale means showed that the scales were negatively skewed (average skewness was 1.0), but that all subscales were skewed to largely the same degree. Consideration was given to transforming the subscale scores. Given that this would render the scores more difficult to interpret and that with larger samples multivariate analyses appear to be robust to the effects of non-normality, ${ }^{14}$ transformation was considered undesirable.

Repeated measures analysis of variance (ANOVA), with the five subscales as the within subjects factor, was used to examine whether there were some aspects of care with which patients were more satisfied than others. According to Tabachnick and Fidell, ${ }^{14}$ it is appropriate to analyze Likert scales using analysis of variance as long as there are a number of categories and the categories represent a quantitative attribute, such as increasing agreement with an item. This analysis demonstrated that patients rated certain aspects of care greater than other dimensions of care, $F$ $(4,243)=11.22, P<0.0001$. Follow-up analyses on the means presented in Table III shows that Respect and 
TABLE II Item analysis showing mean, standard deviation, and percentage of patients who disagree on all items

\begin{tabular}{|c|c|c|c|}
\hline & $\%$ Disagree & Mean & $S D$ \\
\hline I was treated with dignity and respect by the anesthesiologist & 4.2 & 1.50 & 0.90 \\
\hline My anesthesiologist was caring and supportive & 4.5 & 1.61 & 0.97 \\
\hline I was comfortable with the number of caregivers involved in my anesthetic care & 3.9 & 1.50 & 0.88 \\
\hline I had a good understanding of the way in which the anesthetic worked & 7.7 & 1.85 & 1.03 \\
\hline Anesthetic issues that were important to me were addressed thoroughly & 10.9 & 1.98 & 1.18 \\
\hline The anesthetic was an important part of my surgery for me and my family & 3.5 & 1.49 & 0.85 \\
\hline I had a clear understanding of the purpose and/or goals of the anesthetic & 5.4 & 1.53 & 0.90 \\
\hline I was given the opportunity to participate in setting my anesthetic treatment goals & 21.4 & 2.43 & 1.36 \\
\hline My treatment needs, priorities and goals were important to the anesthesiologist & 8.2 & 2.04 & 1.12 \\
\hline I had adequate contact with my anesthesiologist & 19.5 & 2.30 & 1.37 \\
\hline I felt comfortable participating in activities related to my anesthetic care & 7.6 & 1.92 & 1.09 \\
\hline I felt that I was ready for my discharge to the unit or home following the anesthetic & 9.8 & 1.74 & 1.14 \\
\hline I was given adequate information about the anesthetic & 16.5 & 2.10 & 1.25 \\
\hline I have a good understanding of information provided regarding my anesthetic & 13.4 & 2.10 & 1.18 \\
\hline My unanswered questions and needs were addressed regarding the anesthetic & 10.8 & 2.10 & 1.13 \\
\hline My reports of pain were acknowledged by the anesthesiologist & 8.8 & 2.09 & 1.14 \\
\hline My pain was controlled in a satisfactory manner by the anesthesiologist & 6.2 & 1.72 & 1.05 \\
\hline Information about my anesthetic care was provided in a nonthreatening manner & 6.8 & 1.68 & 1.01 \\
\hline My family/friends received information to assist me following my anesthetic & 23.2 & 2.41 & 1.36 \\
\hline I received information which helped me develop my own ways of dealing with pain & 18.2 & 2.28 & 1.29 \\
\hline Tests and procedures related to the anesthetic were adequately explained & 14.2 & 2.12 & 1.24 \\
\hline I had adequate time for rest and sleep following the anesthetic & 7.3 & 1.62 & 1.01 \\
\hline I had input into the extent of involvement by family in my anesthetic care & 23.9 & 2.61 & 1.32 \\
\hline People important to me were treated with respect by the anesthesiologist & 10.3 & 2.11 & 1.18 \\
\hline My need for privacy was respected by the anesthesiologist & 6.7 & 1.89 & 1.02 \\
\hline I felt comfortable expressing my worries to the anesthesiologist & 14.1 & 2.08 & 1.24 \\
\hline I felt at ease with the care provided by the anesthesiologist & 8.8 & 1.73 & 1.10 \\
\hline The anesthesiologist tried to ensure my comfort & 8.2 & 1.78 & 1.09 \\
\hline My physical surroundings were comfortable with respect to the anesthetic & 4.2 & 1.61 & 87 \\
\hline I was able to express my feelings freely to the anesthesiologist & 11.0 & 2.03 & 1.19 \\
\hline My questions about the anesthetic were acknowledged & 9.6 & 1.95 & 1.12 \\
\hline My emotional needs (e.g., worries) were taken seriously by the anesthesiologist & 11.6 & 2.08 & 1.20 \\
\hline I would recommend the anesthesiologist to others & 8.3 & 1.75 & 1.15 \\
\hline I experienced no negative side effects of the anesthetic & 13.4 & 1.81 & 1.23 \\
\hline There were no complications related to the anesthetic & 8.0 & 1.61 & 1.06 \\
\hline
\end{tabular}

Physical Comfort received higher ratings than other dimensions such as Information Provision, Involvement in Care, and Emotional Support.

Multivariate analysis of variance (MANOVA) was used to examine whether ratings on the scales varied as a function of anesthetic type, anesthesiologist, site of service, nature of service (e.g., inpatient $v s$ day surgery), and surgical service. No significant main effects or interactions emerged, suggesting care is uniformly patient-centered across these dimensions.

Table II shows the results of item analysis. There were a number of items on which more than $15 \%$ of respondents gave low ratings of care: I was given the opportunity to participate in setting my care goals; I had adequate contact with my anesthesiologist; I was given adequate information about the anesthetic; My family/friends received information to assist in providing care for me following my anesthetic; I received information which helped me develop my own ways of dealing with pain; and I had input into the extent of involvement by family/friends in my anesthetic care. Others have used a similar cut-off method to identify potential areas that require further examination in order to improve care..$^{15}$

Written feedback from patients was classified as either positive or negative. Consistent with the above analysis, positive comments focused on obtaining physical relief and the anesthesiologist being respectful and friendly. Negative feedback focused on not having an opportunity to meet with the anesthesiologist, and lack of information/understanding regarding the anesthetic. Lack of attention to anxiety and emotional concerns also emerged as a theme in these comments. 
TABLE III Means and standard deviations on subscales

\begin{tabular}{lll}
\hline & Mean & $S D$ \\
\hline Information & 2.00 & 0.92 \\
Involvement & 2.00 & 0.83 \\
Respect & 1.82 & 0.91 \\
Physical comfort & 1.79 & 0.80 \\
Emotional support & 1.94 & 1.02 \\
\hline
\end{tabular}

\section{Discussion}

Clearly, lack of understanding of patient-centered care among patients receiving anesthesia services supports our interest in evaluating these dimensions. It is apparent from the data gathered through this administration of the WCCS that patients generally felt that their anesthetic care met their needs and was acceptable. Subscale scores on the WCCS range from 1 to 5 with higher scores reflecting profound disagreement. That the means on the subscales were 2.0 or lower reflects considerable approval of all aspects of care, including Information Provision, Involvement in Care, Respect, Physical Comfort, and Emotional Support. Furthermore, on a positive note, subscale scores were not observed to differ across sites, surgical services, inpatient or day surgery, types of anesthetic, or anesthesiologists, suggesting care is uniformly patient-centered across areas.

While anesthetic services were meeting patient needs, analyses revealed that certain aspects of care obtained higher ratings than other aspects of care. Specifically, analyses revealed patients felt most positive about the Respect that was shown them and with the Physical Comfort they obtained. Lower ratings were given to the Provision of Information, Involvement in Care, and Emotional Support received from the anesthesiologist. Item analysis and theme analysis of written comments were consistent with the subscale analyses. Results suggest that if care is to be improved, it is in these latter three areas that the most improvement can be achieved. Indeed, Asmundson and Jones ${ }^{13}$ have recommended that scores that fall at or above 2.0 should be interpreted as targets for improvement.

The importance of these aspects of care cannot be overemphasized. Previous research has demonstrated that the vast majority of patients undergoing surgery desire information regarding their anesthetic ${ }^{16}$ and that information provision is related to not only increased satisfaction with anesthetic care, but significantly less pain, fewer days of hospital stay, ${ }^{17}$ and reduced anxiety and need for sedation to relieve emotional suffering and pain. ${ }^{18}$ Evidence also suggests that offering patients the opportunity to be involved in their anesthetic care presents benefits in terms of symptoms, length of stay, ${ }^{19}$ and perceptions of control. ${ }^{20}$ Addressing anxiety and emotional concerns also has proved to be beneficial to care. ${ }^{21}$ Patients with lower anxiety have been found to require lower levels of anesthetic, ${ }^{22}$ have reduced patient-controlled analgesic demands, ${ }^{23}$ and experience lower postoperative pain resulting in earlier discharge. ${ }^{24}$

The patient-centered care survey used in this study addressed multiple aspects of anesthetic care, and serves to heighten our awareness of how patients view anesthesia, as well as the dimensions of care the anesthesiologist needs to concentrate on in order to improve the patient-physician interaction. In this study, the information highlights the need to improve communication with patients in several areas in terms of explaining what is being done, offering the opportunity to involve patients in care, and recognizing and reassuring anxious patients. Others have similarly found the WCCS to be useful for identifying areas of improvement. Among medical patients, for instance, community transition has been identified as a key area of concern among clients. ${ }^{11}$

Whether the results of our study are unique to this study or are generalizable across settings needs to be investigated. Furthermore, whether the results of the present study are generalizable to those who did not respond to the survey also may require further attention. As noted above, the results of the present study are based on a response rate of only $26 \%$. It is impossible to know why patients choose not to respond. One possibility is that patients do not sufficiently care about their anesthetic care to take the time to respond. In this way, respondents may be quite different from non-respondents. Examining the characteristics of respondents compared to non-respondents we found that our sample was older and more likely to be female compared to non-respondents. This would suggest that the results of the study are most likely to be representative of an older female sample. It is commonly believed that for a sample to be representative, the survey's response rate must be high. ${ }^{12}$ In a recent review, Krosnick, however, presents evidence to show that a higher response rate does not necessarily result in a more representative sample. This research reviewed by Krosnick ${ }^{12}$ would suggest that the present study should not be dismissed due to low response rate. Furthermore, in support of some representativeness of the sample in the present study, respondents and non-respondents were not different in terms of nature of surgery, anesthesiologist, service area, or anesthetic type. 
In our setting, administration of the WCCS proved to be valuable. Demonstrating the utility of the measure, the WCCS permitted the department head and members to have a broad overview of the anesthetic care being provided and also served to direct quality improvement initiatives. Following data collection and analysis of the present findings, ratings of care from the study were made available confidentially to each anesthesiologist and the department head. The purpose for doing this was in keeping with Shafer and Fish's ${ }^{25}$ assertion that anesthesiologists, despite being highly procedure-oriented, can benefit from understanding patients' perspectives and experiences of care. Provision of this information served to broaden anesthesiologists' views of quality care beyond that of physical signs and symptoms, to encompass other important elements of care. Furthermore, the Department of Anesthesiology used this information to direct a quality improvement initiative. Currently, within the RHD, preoperative anesthetic education is delivered most often by a nurse in pre-admission clinics for the vast majority of patients, and by an anesthesiologist for a much smaller group of medically complex patients. In both cases, preoperative education on the anesthetic is designed to ensure the readiness of the patient for anesthesia, to educate the patient regarding the chosen anesthetic method, to provide reassurance and alleviate anxiety, and to inform the patient of postoperative care and pain management. Based on findings from the present study, it is apparent that there are numerous patients whose needs for information, reassurance, and involvement are not being met with the current method of service delivery. As a first method for addressing this concern, the department requested that surgeons and nurses attempt to identify patients who require further individual consultation with an anesthesiologist. A commitment was made to provide expanded coverage to address and alleviate patients' information and emotional concerns and to include patients in service delivery. Beyond making themselves available, attention may also need to be given to the quality of information provision, as well as the strategies for dealing with emotional concerns and involving patients in care.

In summary, it appears that overall anesthetic care is relatively patient-centered, and that regardless of the nature of care, patients' ratings of care are reasonably positive. Our findings, however, have relevance for building and tailoring a patient-centered approach to anesthetic care. Specifically, the results of this study emphasize the value in assessing anesthetic outcomes in terms of not only Physical Comfort, but other dimensions of care such as Information Provision, Involvement, Emotional Support, and Respect. The results also demonstrate how the surveys can be used to direct the department in improving and customizing future anesthetic service delivery to ensure not only the patients' physical needs are met, but their psychosocial needs are met as well.

\section{Acknowledgements}

Appreciation is extended to the patients who participated in this project and provided insightful comments into anesthetic care in the RHD. We would also like to acknowledge Dr. Gordon Asmundson and Sylvia Jones for permitting us to use the WCCS. Acknowledgements are also extended to Linda Picot and Allisson Quine for assistance with data collection, and Regan HartMitchell for assistance with data analysis.

\section{References}

1 Cleary PD, Edgman-Levitan S, Walker JD, Gerteis M, Delbanco TL. Using patient reports to improve medical care: a preliminary report from 10 hospitals. Quality Management in Health Care 1993; 2: 31-8.

2 Edgman-Levitan S, Gerteis M. Patient confidence in the health care system. IHI Quality Connection 1998; 7: $1-2$.

3 Gerteis $M$, Edgman-Levitan S, Walker JD, Stoke DM, Cleary PD, Delbanco TL. What patients really want. Health Management Quarterly 1993; 15: 2-6.

4 Lutz BJ, Bowers BJ. Patient-centered care: understanding its interpretation and implementation in health care. Sch Inq Nurs Pract 2000; 14: 165-82.

5 Gerteis M, Edgman-Levitan S, Daley J, Delbanco TL. Medicine and health from the patient's perspective. In: Gerteis M, Edgman-Levitan S, Daley J, Delbanco TL (Eds.). Through the Patient's Eyes: Understanding and Promoting Patient-Centered Care. San Francisco: Jossey-Bass, 1993: 1-5.

6 Macario A, Weinger M, Carney S, Kim A. Which clini$\mathrm{cal}$ anesthesia outcomes are important to avoid? The perspective of patients. Anesth Analg 1999; 89: 652-8.

7 Preble LM, Perlstein L, Katsoff-Seidman L, O'Connor $T Z$, Barash PG. The patient care evaluation system: patients' perception of anesthetic care. Conn Med 1993; 57: 363-6.

8 Fung D, Cohen MM. Measuring patient satisfaction with anesthesia care: a review of current methodology. Anesth Analg 1998; 87: 1089-98.

9 Pascoe GC. Patient satisfaction in primary health care: a literature review and analysis. Evaluation Program Planning 1983; 6: 185-210.

10 Le May S, Dupuis G, Harel F, Taillefer M-C, Dubé S, Hardy J-F. Clinimetric scale to measure surgeons' satisfaction with anesthesia services. Can J Anesth 2000; 47: 398-405 
11 Asmundson GJG, Jones S. WCCS-R User's Manual 2000. Regina, Saskatchewan: Regina Health District Press, 2000.

12 Krosnick JA. Survey research. Annu Rev Psychol 1999; 50: 537-67.

13 Asmundson GJG, Jones $S$. The Wascana client-centered care survey: development and psychometric evaluation. Canadian Journal of Quality in Health Care 1996; 13: 19-21.

14 Tabachnick BG, Fidell LS. Using Multivariate Statistics, $3^{\text {rd }}$ ed., New York: HarperCollins College Publishers, 1996.

15 Burroughs TE, Cira JC, Chartock P, Davies AR,

Dunagan $W C$. Using root cause analysis to address patient satisfaction and other improvement opportunities. Journal on Quality Improvement 2000; 26 : 439-49.

16 Lonsdale M, Hutchinson GL. Patients' desire for information about anaesthesia: Scottish and Canadian attitudes. Anaesthesia 2000; 46: 410-2.

17 Miaskowski C, Crews J, Ready LB, Paul SM, Ginsberg B. Anesthesia-based pain services improve the quality of postoperative pain management. Pain 1999; 80: 23-9.

18 Bondy LR, Simms N, Schroeder DR, Offord KP, Narr $B J$. The effects of anesthetic patient education on preoperative patient anxiety. Reg Anesth Pain Med 1999; 24: 158-64.

19 Lawlis GF, Selby D, Hinnant D, McCoy CE. Reduction of postoperative pain parameters by presurgical relaxation instructions for spinal pain patients. Spine 1985; 10: 649-51.

20 Chumbley GM, Hall GM, Salmon P. Patient-controlled analgesia: an assessment by 200 patients. Anaesthesia 1998; 53: 216-21.

21 Klopfenstein CE, Forster A, Van Gessel E. Anesthetic assessment in an outpatient consultation clinic reduces preoperative anxiety. Can J Anesth 2000; 47: 511-5.

22 Maranets $I$, Kain $Z N$. Preoperative anxiety and intra operative anesthetic requirements. Anesth Analg 1999 89: 1346-51.

23 Gil KM, Ginsberg B, Muir M, Sykes D, Williams DA. Patient-controlled analgesia in postoperative pain: the relation of psychological factors to pain and analgesic use. Clin J Pain 1990; 6: 137-42.

24 Perry F, Parker RK, White PF, Clifford PA. Role of psychological factors in postoperative pain control and recovery with patient-controlled analgesia. Clin J Pain 1994; 10: 57-63; 82-5.

25 Shafer A, Fish MP. A call for narrative: the patient's story and anesthesia training. Lit Med 1994; 13: $124-42$. 